Pak. j. sci. ind. res. Ser. B: biol. sci. 2017 60(3) 145-153

\title{
Application of Spectroscopic Techniques for Antioxidant Property Analysis of Various Food Supplements and Ganoderma lucidum Coffee
}

\author{
Zeynep Aygun \\ Bitlis Eren University, Vocational School of Technical Sciences, Bitlis, Turkey
}

(received August 29, 2016; revised January 10, 2017; accepted February 10, 2017)

\begin{abstract}
In the present study, different methods were used to investigate the magnetic and structural properties of some food supplements and a kind of Ganoderma lucidum coffee. In order to understand the antioxidant capability of the samples and to detect paramagnetic centres, EPR (Electron Paramagnetic Resonance) experiment was carried out at room temperature. To examine the structural features and crystalline property of the samples, XRD (X-ray diffraction) method was used. SEM (Scanning Electron Microscopy) technique was preferred to analyse the surface morphology. Also, EDS (Energy Dispersive Spectroscopy) was performed to get information about the elemental composition of the samples. Antioxidant potential of these samples were examined in detail which is important to support our body functions.
\end{abstract}

Keywords: antioxidant property, coffee, food supplements, Ganoderma lucidum

\section{Introduction}

With a balanced diet containing sufficient amounts of main nutrients such as protein carbohydrate and fat, it is necessary to provide minerals and vitamins required by the body. Some additional vitamins are also required for various bodily functions, for instance, pregnancy, lactation, a study over the daily performance, puberty, long-term diseases, some pathological cases, local features or genetic features. Such nutritional supplements, however, may also have negative effects on different groups of people, like children, pregnant and nursing women or elderly people therefore, using these kind of products it should be careful. In order to supply normal diet, like amino acids, vitamins, minerals, protein, carbohydrates, fibre, fatty acids, vegetable and animal derived ingredients are called as food supplements (www.tarin.gov.tr, 2016) and these products have great interest.

An alternative product used commonly in worldwide especially in China and other far east countries is a type of coffee made of Ganoderma lucidum. Ganoderma lucidum (also named as Reishi or Ling Zhi) is a whiterot fungi and a traditional medicine which has been used for over 4000 years in these far east countries because of its medicinal properties. Ganoderma lucidum contains about 400 different bioactive compounds, like triterpenoids, polysaccharides, nucleotides, sterols, steroids, fatty acids, proteins, peptides and trace elements E-mail: zeynep.yarbasi@gmail.com
(Manavalan et al., 2015; Paul et al., 2015). Modern pharmacological and clinical investigations demonstrated that Ganoderma lucidum exhibits antitumor and immunomodulatory activities (Lin and Zhang, 2004). Since Ganoderma lucidum fungi has been used to prevent and to treat several diseases for a long time, these properties make this type of coffee attractive to examine.

On behalf of issues mentioned above, it seems to be necessary to investigate these products which people use in their daily life to support their bodily functions in terms of antioxidant properties. Antioxidants can react with free radicals and prevent the reaction before vital molecules are damaged. The reaction takes place in several ways (i) they may diminish the energy of the free radical, (ii) stop the free radical from forming in the first place and (iii) minimize the damage caused by free radicals (Yarbasi et al., 2011). Recently, because of great interest many studies about antioxidant properties of different samples have been reported by Ballesteros et al. (2015), Pasanphan et al. (2010) and Zeng et al. (2010).

In this paper, the structural properties of some food supplements and Ganoderma lucidum coffee, have been investigated spectroscopically which have antioxidant potentials due to their ingredients. First of all, the samples have been analysed by EPR (Electron Paramagnetic Resonance) spectroscopy. EPR spectroscopy is efficiently performed as a skillfull tool in food researches 
because of the ability of detecting free radicals and paramagnetic centers that have one or more unpaired electrons for identification of damages in irradiated food-stuffs, chelating properties of antioxidant samples in some food (Biyik and Tapramaz, 2009) and antioxidant potential of the samples may be detected by this technique. Additionally, XRD (X-ray diffraction) experiments was performed to get information about the chemical compositions and crystalline properties of these structures. With the aim of having knowledge in detail about the surface morphology of the samples, SEM (Scanning Electron Microscopy) was used. Also, EDS (Energy Dispersive Spectroscopy) method was used to determine the elemental compositions.

Some work has been carried out with Ganoderma lucidum for different purposes (Manavalan et al., 2015; Álvarez et al., 2014; Lin and Zhang, 2004). But, to our knowledge there is no paper reported for these products with EPR, XRD and SEM techniques to see the antioxidant property, hence, the present study was conducted to report magnetic and structural properties of food supplements and coffee.

\section{Materials and Methods}

Sample preparation. Three kinds of food supplements were purchased from Nutriway ${ }^{(\mathrm{TM})}$ (legume complex, glucosamine boswellia, calcium-magnesium complex) and Ganoderma lucidum coffee from local sellers commercially. One pill for each food supplements was used. All samples, except Ganoderma lucidum powder, were ground in a mortar prior to spectroscopic analysis.

Ganoderma lucidum coffee was prepared in a similar way as in our daily consumption. $100 \mathrm{~mL}$ domestic water was boiled, a packet of coffee was added to boiled water and it was stirred with a wooden spoon until dissolved. This mixture was left for evaporation at room temperature and to investigate in powder form dried sample was taken for study.

Instrumentation. An X-band JEOL JESFA-300 EPR spectrometer with $100 \mathrm{kHz}$ modulation field and $\approx 9.23$ $\mathrm{GHz}$ frequency was used for recording EPR spectra of three food supplements and two coffee samples at room temperature. Diamagnetic tubes were used for samples in the powder form performing by EPR spectrometer.

The XRD patterns of samples were obtained using BRUKER D8 ADVANCE XRD, which was operated at $40 \mathrm{kV}$ and $40 \mathrm{~mA}$ with a scanning speed of $2.5^{\circ} / \mathrm{min}$.
$\mathrm{Cu} \mathrm{K} \alpha$ radiation of wavelength $\lambda=1.54060 \AA$ was used and data was taken for the $2 \theta$ range of $3^{\circ}-90^{\circ}$.

In SEM technique, an electron gun with thermoionic emission is usually used for producing electron. Electrons are accelerated in high voltage $(1-30 \mathrm{keV})$ and condenser lenses are used to demagnify electron beam until it has a diameter of approximately $10 \mathrm{~nm}$. The signals composed of the interaction between incident electron beam and sample give us different information about the specimen. The scanning electron microscope images of powders were measured by JEOL JSM-6610 SEM spectrometer. Also, EDS analysis of the samples were performed.

\section{Results and Discussion}

The EPR spectra of three kinds of food supplements and Ganoderma lucidum coffee samples have been recorded at room temperature. The obtained $g$-factor of the EPR lines have been calculated from the equation

$$
h v=g \beta H
$$

where:

$H=$ the magnetic field; $v=$ the microwave frequency; $h=$ the Planck constant and $\beta=$ the electron Bohr magneton.

Spectroscopic results for food supplements. EPR experiment of food supplements was carried out at room temperature. For the first sample (legume complex), from EPR spectrum (Fig. 1a), a singlet with a $g$ value of 2.0036 and linewidth of $9.95 \mathrm{G}$ was obtained. Likewise, as seen from (Fig. 1b), an EPR signal of second sample (glucosamine boswellia) with a $g$ value of 2.0037 and linewidth of $9.95 \mathrm{G}$ was observed. For the third kind of sample (Ca-Mg complex) shown in (Fig. 1c), an EPR singlet with $\mathrm{g}=2.0046$ and linewidth of $7.4 \mathrm{G}$ and $\mathrm{Mn}(\mathrm{II})(I=5 / 2)$ six hyperfine lines ( $\mathrm{g}_{\mathrm{iso}} \approx 2.00$ ) was seen. It can be seen in Fig. 1c. that there is a weak signal, marked by an arrow, and overlapping with the Mn(II) sextet lines (Yarbasi et al., 2011). Since samples of food supplements have linewidths close to each other, there are dipolar interactions between free radicals in close values (Krakowian et al., 2014). Also, the forbidden transition lines (five weak doublets) of $\operatorname{Mn}(\mathrm{II})\left(\Delta \mathrm{m}_{\mathrm{l}}= \pm 1\right)$ are observed and denoted by asterisks (Bennur et al., 2001). The $g$ values determined for these three samples can be evaluated as a result of presence of organic free radical which is also mentioned in previous reports 


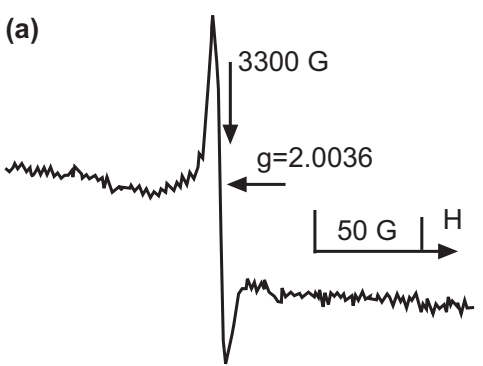

(b)
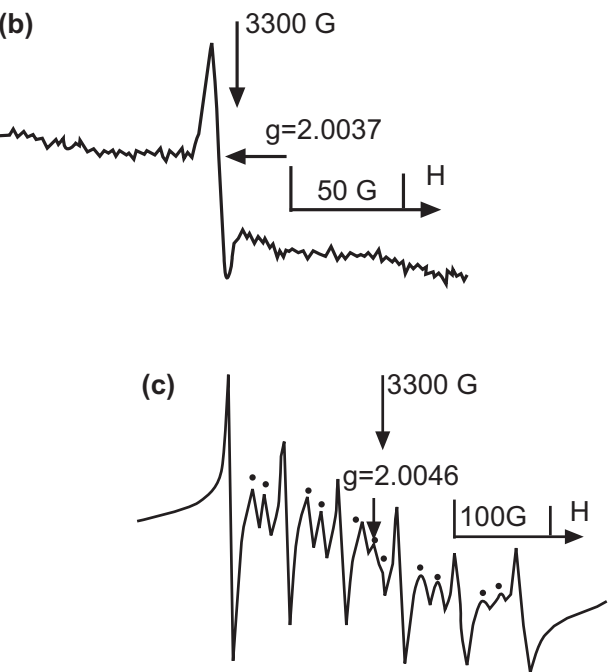

Fig. 1. EPR spectra of (a) legume complex (b) glucosamine boswellia (c) Ca-Mg complex recorded at room temperature.

(Ukai et al., 2008; Shimoyama et al., 2007; Commoner et al., 1957). In previous studies, diverse evaluations were made about the origin of this singlet, as free radicals of semi-quinones, lignin or due to oxidation of fatty acids visible in some vegetables, phenols and/or flavonoids (Yarbasi et al., 2011).

XRD study of food supplements was carried out at room temperature, and the patterns are given in Fig. 2. According to the XRD of three food supplement samples, peak sharpness shows the crystalline property clearly (Fig. 2a-c). Peak positions of the samples were given with corresponding compounds in XRD figures. For legume complex (Fig. 2a), main peak is centered at $22.5^{\circ}$ attributed to cellulose (Vivekanandhan et al., 2012) and $\mathrm{SiO}_{2}$ (Ferreira et al., 2015). Other less intense and broad peak at $34.7^{\circ}$ corresponds with microcrystalline cellulose as mentioned in a previous paper (Vivekanandhan et al., 2012). In Fig. 2b, many sharp and intense peaks centered at $2 \theta=16.5^{\circ}, 22.9^{\circ}, 24.0^{\circ}$,

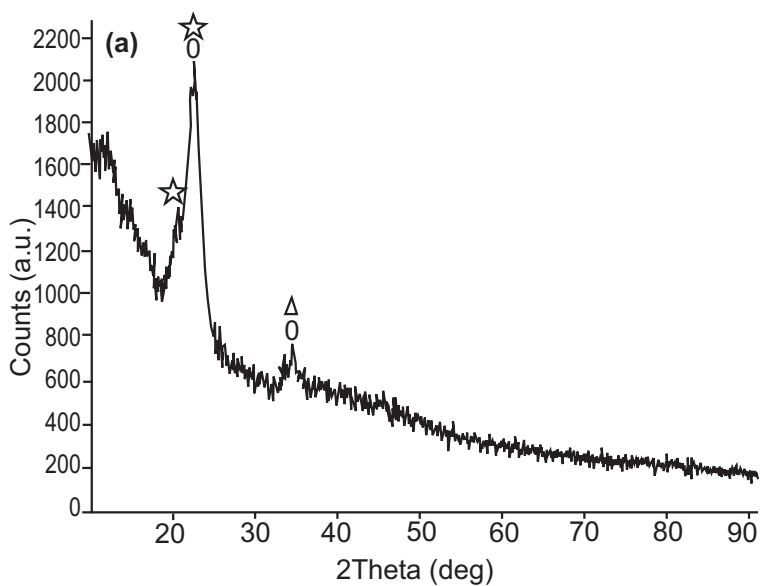

0 Cellulose; $\Delta \mathrm{CaCO}_{3} ; \dot{\sim} \overrightarrow{\mathrm{r}} \mathrm{SiO}_{2}$

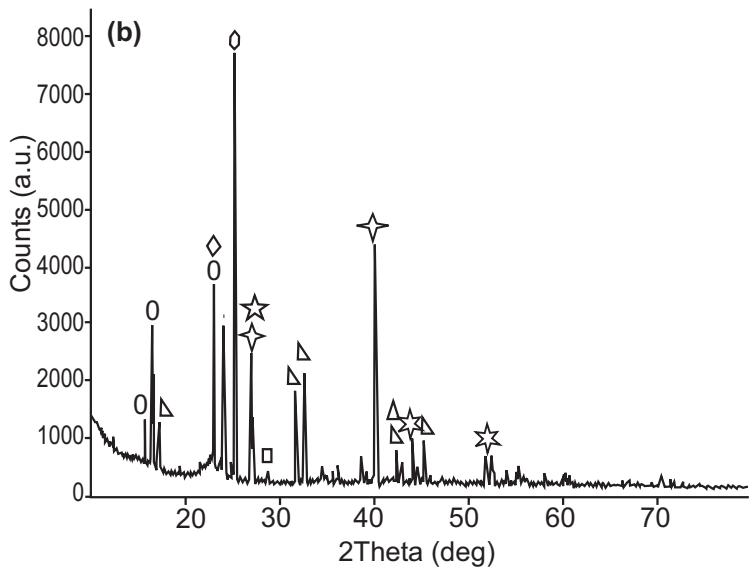

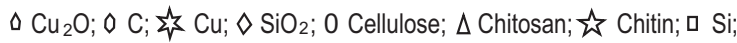

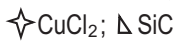

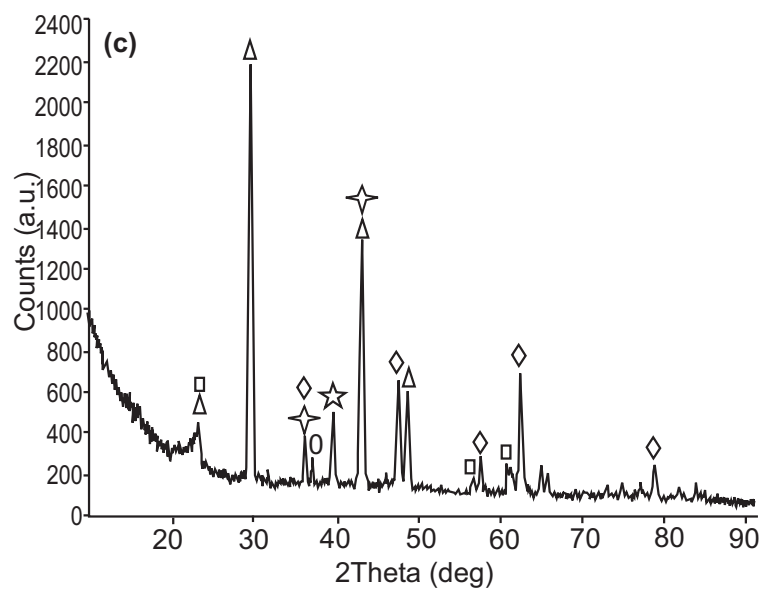

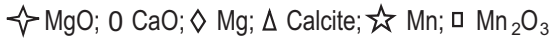

Fig. 2. XRD patterns of (a) legume complex (b) glucosamine boswellia (c) $\mathrm{Ca}-\mathrm{Mg}$ complex recorded at room temperature. 
$25.2^{\circ}, 26.8^{\circ}, 31^{\circ}, 32^{\circ}, 40.1^{\circ}$ were detected in glucosamine boswellia. The most intense and sharp peak located at $25.2^{\circ}$ was assigned as $\mathrm{C}$ peak (Mahanandia et al., 2011). As given in Fig. 2c, for Ca-Mg sample, main sharp peaks are seen at $23.1^{\circ}, 29.5^{\circ}, 36.1^{\circ}, 39.5^{\circ}$,
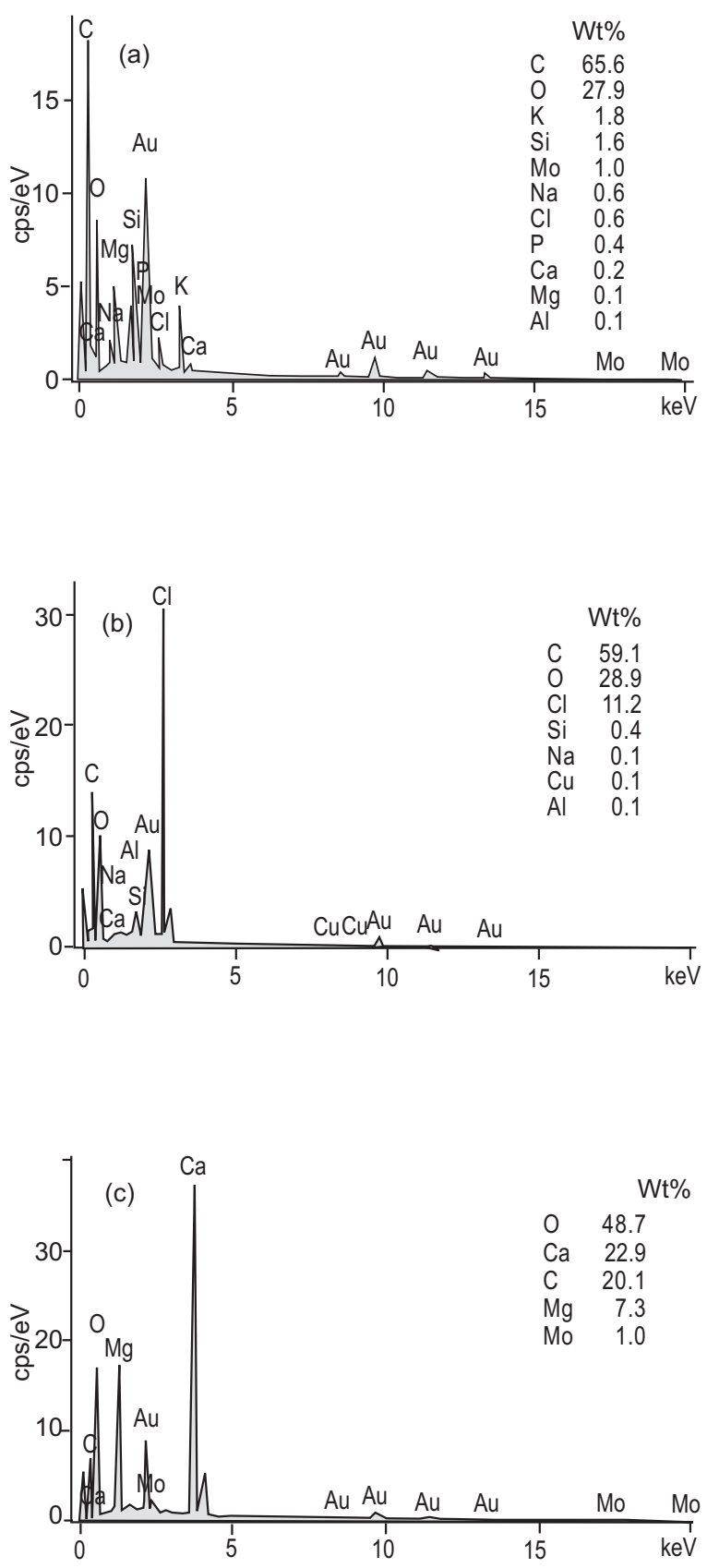

$43.0^{\circ}, 47.5^{\circ}, 48.6^{\circ}, 57.5^{\circ}$ and $62.4^{\circ}$. Peaks centered at $29.5^{\circ}, 39.5^{\circ}, 43.0^{\circ}, 47.5^{\circ}, 48.6^{\circ}, 57.5^{\circ}$ and $62.4^{\circ}$ are characteristics of calcite $\left(\mathrm{CaCO}_{3}\right)$ as given by Rahman et al. (2013). These calcite peaks were also observed in previous studies reported for oyster shell (Wu et al.,
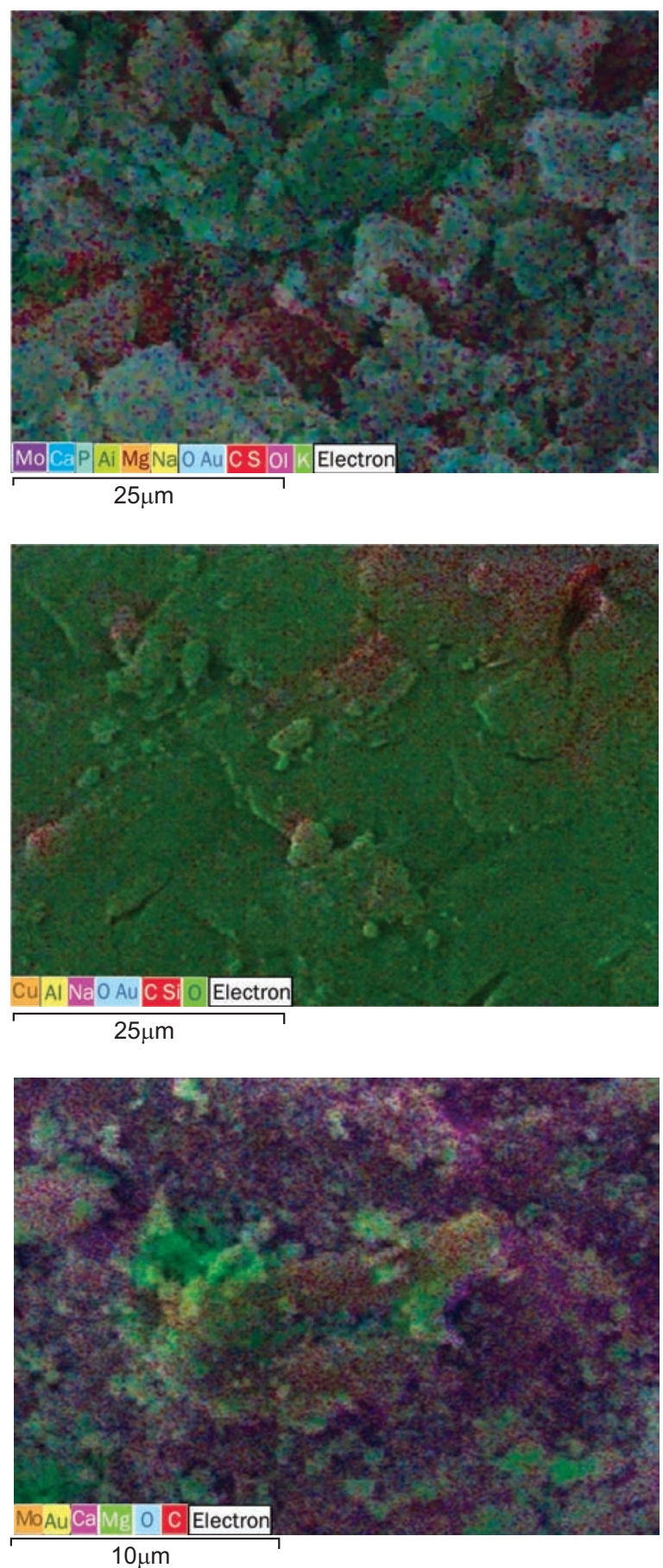

Fig. 3. EDS pattern of (a) legume complex (b) glucosamine boswellia (c) Ca-Mg complex obtained at room temperature. 
2011; Yoon et al., 2004) and oyster shell is one of the $\mathrm{Ca}-\mathrm{Mg}$ ingredients sample.
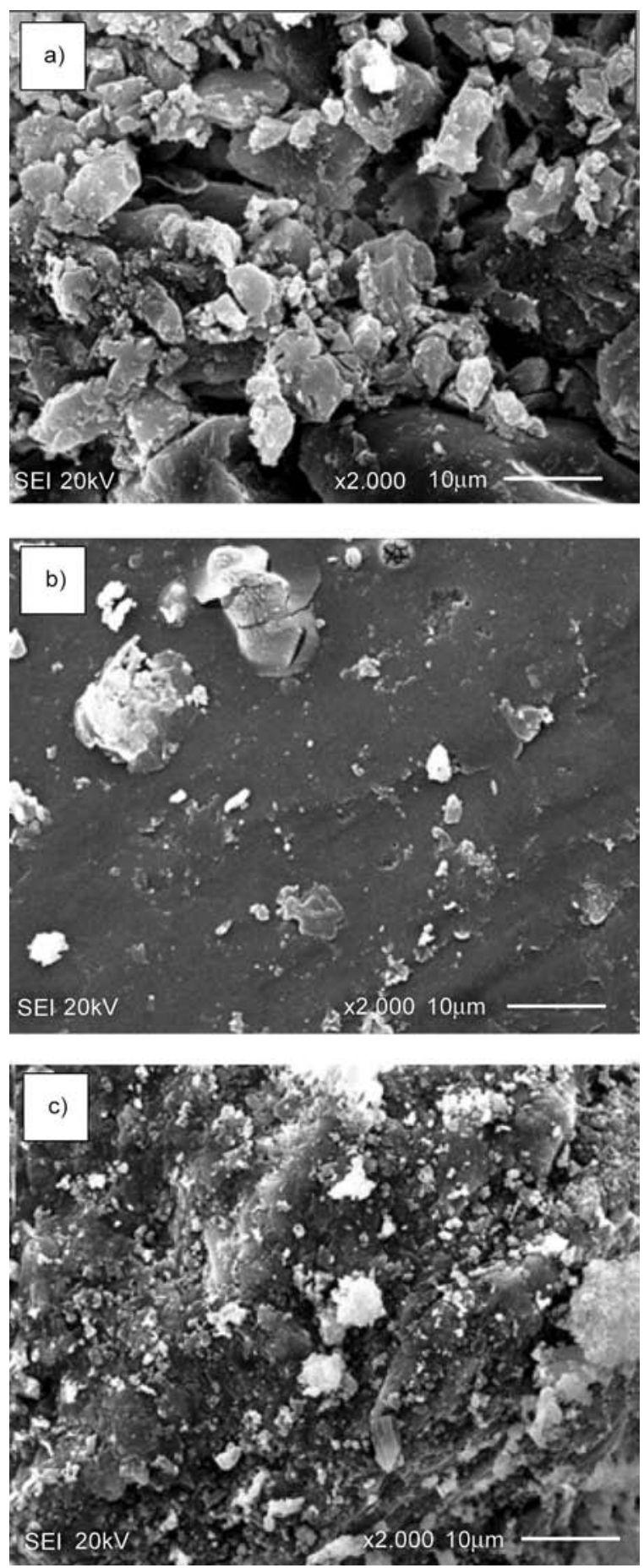

Fig. 4. SEM pictures of (a) legume complex (b) glucosamine boswellia (c) Ca-Mg complex recorded at room temperature.
EDS measurements of food supplements were carried out at room temperature to determine the elemental compositions and obtained results are given in Fig. 3. As seen from the observed peaks, the ingredients with weight percent of the food supplements are in good agreement with XRD measurements. Although Mn(II) hyperfine lines in EPR spectrum and $\mathrm{Mn}$ (II) peak in XRD pattern were observed, no $\mathrm{Mn}$ (II) peak was seen in EDS pattern. This may be because of the too small weight percent of $\mathrm{Mn}(\mathrm{II})$ in the structure.

In SEM experiments, secondary electrons (SE, inelastic scattering) are used for determining sample morphology (topography), back-scattered electrons (BSE, elastic scattering) are important for analyzing sample composition (Aygun, 2013). SEM pictures of food supplements have been recorded at room temperature and given in Fig. 4. Microstructure properties are seen from micrographs and microcrystalline structure of all the samples can be defined.

Spectroscopic results of Ganoderma lucidum coffee. EPR spectra of Ganoderma lucidum coffee were recorded at room temperature and given in Fig. 5. From the EPR spectrum of the coffee without any treatment, an EPR singlet with $g=2.0034$ and linewidth $9.05 \mathrm{G}$ ( Fig. 5a) has been observed. This kind of signal with $\mathrm{g}=2.0039$ and linewidth $9.95 \mathrm{G}$ has also been obsedrved for coffee consumed in our daily life (Fig. 5b). The linewidths are close to each other so dipolar interactions between free radicals are in close values. The obtained $g$ values can be attributed to a carbon centered organic radical

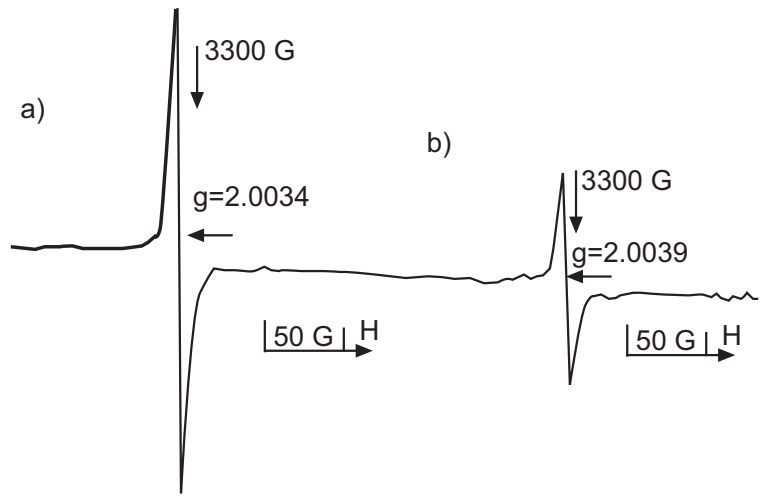

Fig. 5. EPR spectra of (a) untreated-coffee (Ganoderma lucidum) (b) treated-coffee (Ganoderma lucidum) recorded at room temperature. 
(Ukai et al., 2008; Shimoyama et al., 2006). The main difference between these EPR signals is line intensity. For both samples, treated and untreated, measured radical values are the same, so it can be said that the antioxidant property is existing for either samples.

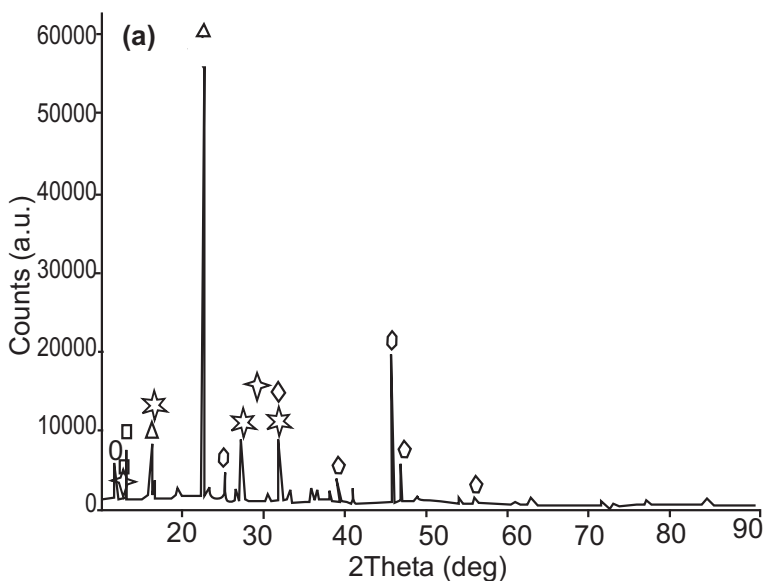

OC 0 Chitosan $\triangle$ Cellulose $\mathrm{uChitin} \&$ Caffeine

放white sugar $\Delta \mathrm{Ta}_{2} \mathrm{O}_{3} \diamond \mathrm{Na}_{2} \mathrm{O}$
Likewise, the XRD pattern of untreated Ganoderma lucidum coffee in crystalline phase is given in Fig. 6a. Peak positions have been evaluated with peak sharpness. Main intense peaks are located at $11.8^{\circ}, 13.2^{\circ}, 22.5^{\circ}$, $27.3^{\circ}, 32.0^{\circ}, 46.0^{\circ}$ and $47.0^{\circ}$. The peak located at $47.0^{\circ}$

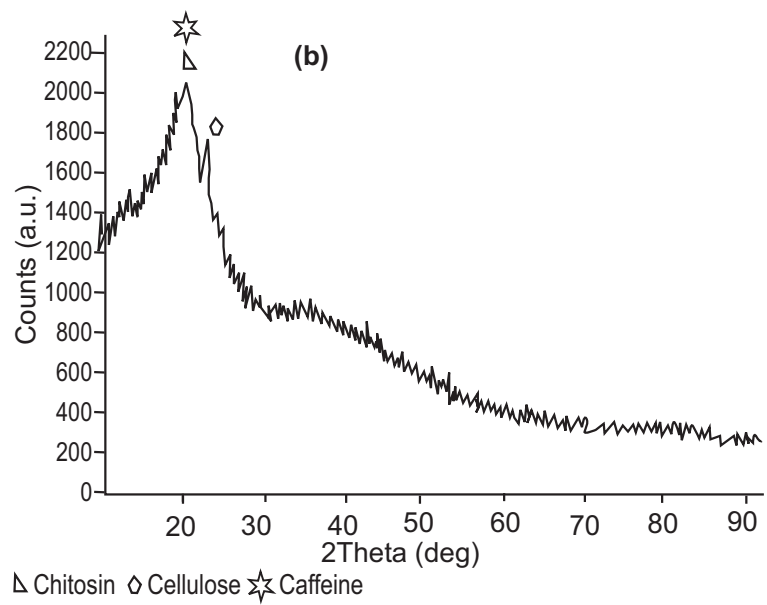

Fig. 6. XRD patterns of (a) untreated-Ganoderma lucidum coffee (b) treated-Ganoderma lucidum coffee recorded at room temperature.
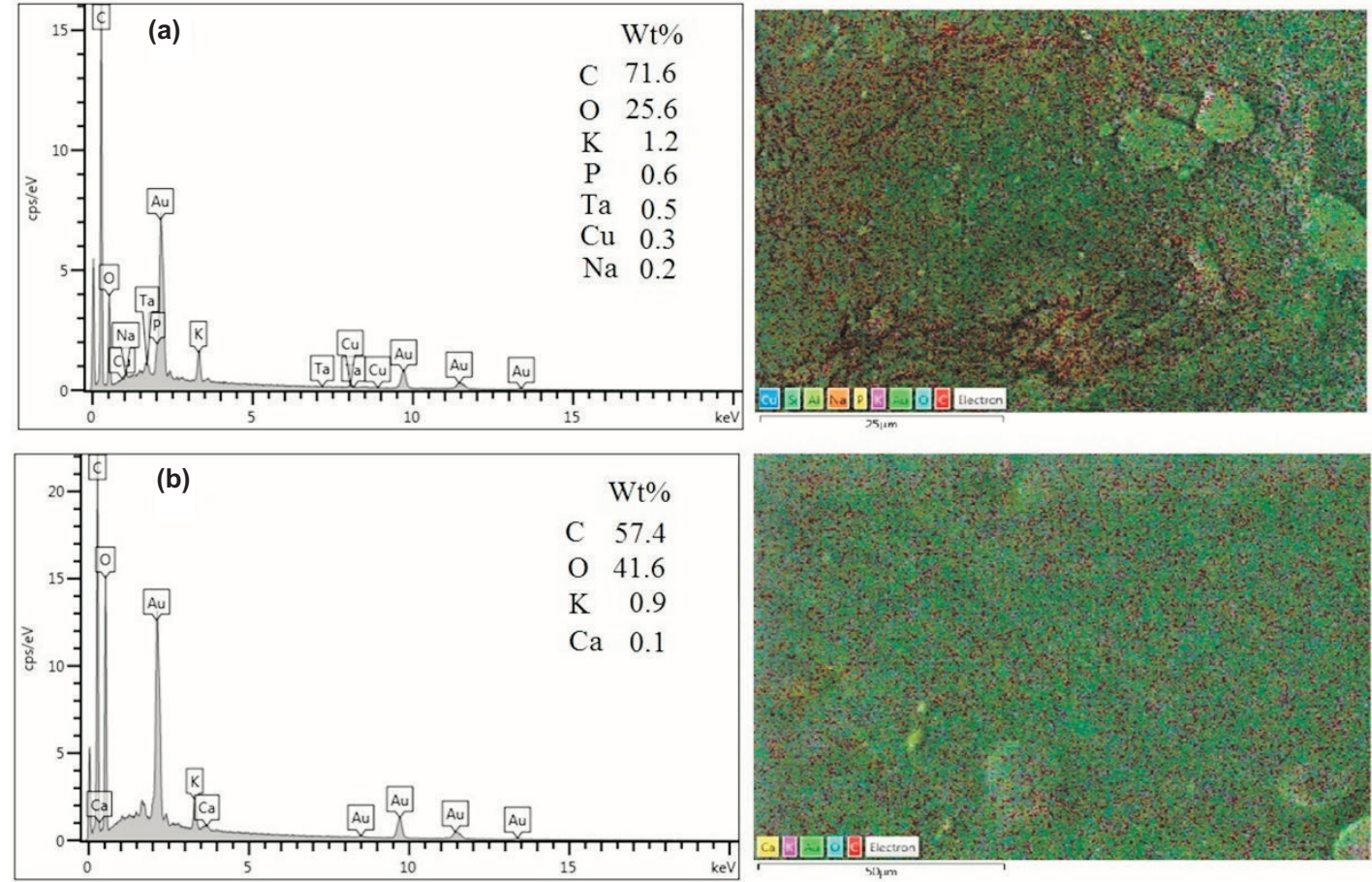

Fig. 7. EDS results of (a) untreated-Ganoderma lucidum coffee (b) treated-Ganoderma lucidum coffee obtained at room temperature. 
is reported as $\mathrm{Ta}_{2} \mathrm{O}_{5}$ by Hara et al. (2003). One of the main peak centered at $22.5^{\circ}$ was assigned as cellulose and chitosan (Pasanphan and Chirachanchai, 2008). But for treated-coffee, crystalline property could not be determined clearly. Because of broad lines (Fig. 6b), it could be said that treated coffee has shown amorphous structure compared with untreated coffee. Main peak located at $21.2^{\circ}$ can be attributed to caffeine (Rivera et al., 2011) and $21.2^{\circ}$ and $23.3^{\circ}$ may be assigned as cellulose (Ballesteros et al., 2015; Chen et al., 2013) (Fig. 6b). Some of the peaks are labelled as chitin, chitosan and cellulose for glucosamine boswellia and untreated-coffee. Chitin and chitosan, after cellulose,
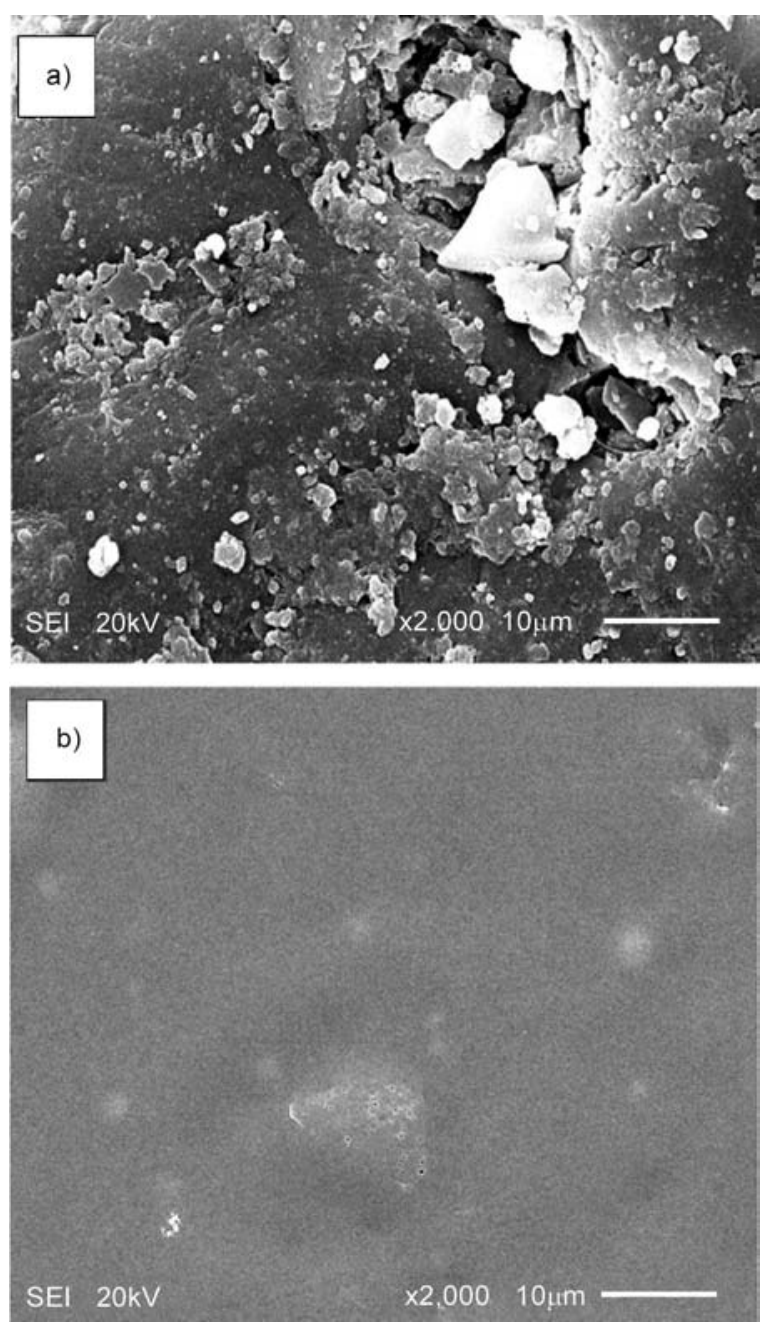

Fig. 8. SEM pictures of (a) untreated-Ganoderma lucidum coffee (b) treated-Ganoderma lucidum coffee recorded at room temperature. together constitute the second-most naturally abundant copolysaccharides. These polymers are obtained from the shells of crustaceans, such as shrimps, crabs and lobsters, and the cell walls of fungi and yeasts (Kumirska et al., 2010; Pasanphan et al., 2010).

EDS measurements of untreated and treated Ganoderma lucidum coffee was carried out at room temperature to determine the elemental compositions and obtained results are shown in Fig. 7. As seen from the results, XRD peak positions determined for samples are compatible with elemental EDS analysis. SEM pictures of Ganoderma lucidum coffee were recorded at room temperature and are given in Fig. 8. Microstructure properties are seen in the pictures and microcrystalline structure can be detected for untreated-coffee. An amorphous property can be observed from treated-coffee SEM photograph (Fig. 8).

Domestic water was used to prepare the Ganoderma lucidum coffee as in our daily consumption. So, relatively high impurities in domestic water might affect the results of XRD, SEM or EDS. This case can be studied as an other research topic by using distilled water.

\section{Conclusion}

In this study, the obtained results can be summarized as follows:

i) For all kind of samples, an EPR singlet has been obtained that corresponds to organic free radical. Only for Ca-Mg sample manganese sextet overlapped with EPR line was detected in EPR spectrum.

ii) As shown in EPR spectra, samples of food supplements have linewidths close to each other. There are dipolar interactions between free radicals in close values. This result has also been observed for Ganoderma lucidum coffee.

iii) By the help of SEM images, the surface features and morphology of the specimens are seen. Three food supplements and untreated-coffee samples have shown microcrystalline property, while it can not be clearly determined for treatedcoffee.

iv) EDS results give us the elemental compositions of the samples. This data is in agreement with the other experimental results in limitations of device sensitivity.

v) From XRD patterns, it is concluded that the crystalline structure of the samples are observed with sharp and intense peaks. Only for treated- 
Ganoderma lucidum coffee, an amorphous property has been seen.

vi) On behalf of these coherent results of the methods, it is concluded that these investigated food supplements and coffee with Ganoderma lucidum can be evaluated for their antioxidant potential.

\section{References}

Álvarez, S.P.O., Cadavid, D.A.R., Sierra, D.M.E., Orozco, C.P.O., Vahos, D.F.R., Ocampo, P.Z., Atehortúa, L. 2014. Comparison of extraction methods of chitin from Ganoderma lucidum mushroom obtained in submerged culture. Biomedical Research International, 1-7.

Aygun, Z. 2013. AFM and SEM studies of $\mathrm{VO}^{2+}$ doped potassium dihydrogen citrate single crystal obtained by slow evaporation method. Journal of Chemical Crystallography, 43: 103-107.

Ballesteros, L.F., Cerqueira, M.A., Teixeira, J.A., Mussatto, S.I. 2015. Characterization of polysaccharides extracted from spent coffee grounds by alkali pretreatment. Carbohydrate Polymers, 127: 347-354.

Bennur, T.H., Srinivasan, D., Ratnasamy, P. 2001. EPR spectroscopy of copper and manganese complexes encapsulated in zeolites. Microporous and Mesoporous Materials, 48: 111-118.

Biyik, R., Tapramaz, R. 2009. An EPR study on tea: Identification of paramagnetic species, effect of heat and sweeteners. Spectrochimica Acta A, 3: 767-770.

Chen, Q., Wang, Q., Mitsumura, N., Niida, H. 2013. Improved cellulose by ionic liquid mixture with solid acid catalysis and its application in polyethylene glycol liquification. Materials Sciences and Applications, 4: 839-845.

Commoner, B., Heise, J.J., Lippincott, B.B., Norberg, R.E., Passonneau, J.V., Townsend, J. 1957. Biological activity of free radicals. Science, 3263: 57-63.

Ferreira, C.S., Santos, P. L., Alves, B.J., Passos, R.R., Pocrifk, L.A. 2015. Rice husk reuse in the preparation of $\mathrm{SnO}_{2} / \mathrm{SiO}_{2}$ nanocomposite. Materials Research, 3: 639-643.

Hara, M., Hitoki, G., Takata, T., Kondo, J.N., Kobayashi, H., Domen, K. 2003. TaON and $\mathrm{Ta}_{3} \mathrm{~N}_{5}$ as new visible light driven photocatalysts. Catalysis Today, 78: $555-560$.

Krakowian, D., Skiba, S., Kudelsk, A., Pilawa, B.,
Ramos, P., Adamczyk, J., Góral, K.P. 2014. Application of EPR spectroscopy to the examination of pro-oxidant activity of coffee. Food Chemistry, 151: 110-119.

Kumirska, J., Czerwicka, M., Kaczyñski, Z., Bychowska, A., Brzozowski, K., Thöming J., Stepnowski, P. 2010. Application of spectroscopic methods for structural analysis of chitin and chitosan. Marine Drugs, 5: 1567-1636.

Lin, Z.B., Zhang, H.N. 2004. Anti-tumor and immunoregulatory activities of Ganoderma lucidum and its possible mechanisms. Acta Pharmacologica Sinica, 11: 1387-1395.

Mahanandia, P., Schneider, J.J., Engel, M., Stühn, B., Subramanyam, S.V., Nanda, K.K. 2011. Studies towards synthesis, evolution and alignment characteristics of dense, millimeter long multiwalled carbon nanotube arrays. Beilstein Journal of Nanotechnology, 2: 293-301.

Manavalan, T., Manavalan, V., Thangavelu, K.P., Kutzner, A., Heese, K. 2015. Characterization of a solvent-tolerant manganese peroxidase (mnp) from Ganoderma lucidum and its application in fruit juice clarification. Journal of Food Biochemistry, 6: 754-764.

Pasanphan, W., Buettner, G.R., Chirachanchai, S. 2010. Chitosan gallate as a novel potential polysaccharide antioxidant: an EPR study. Carbohydrate Research, 345: 132-140.

Pasanphan, W., Chirachanchai, S. 2008. Conjugation of gallic acid onto chitosan: An approach for green and water-based antioxidant. Carbohydrate Polymers, 72: 169-177.

Paul, S., Singh, A.R.J., Sasikumar, C.S. 2015. Green synthesis of bio-silver nanoparticles by Parmelia perlata, Ganoderma lucidum and Phellinus igniarius and their fields of application. Indian Journal of Research in Pharmacy and Biotechnology, 2: 100-110.

Rahman, M.A., Halfar, J., Shinjo, R. 2013. X-Ray diffraction is a promising tool to characterize coral skeletons. Advances in Materials Physics and Chemistry, 3: 120-125.

Rivera, W., Velascoa, X., Gálveza, C., Rincóna, C., Rosalesb, A., Arango, P. 2011. Effect of the roasting process on glass transition and phase transition of Colombian Arabic coffee beans. Procedia Food Science, 1: 385-390.

Shimoyama, Y., Ukai, M., Nakamura, H. 2007. Advanced protocol for the detection of irradiated food by electron spin resonance spectroscopy. Radiation 
Physics and Chemistry, 76: 1837-1839.

Shimoyama, Y., Ukai, M., Nakamura, H. 2006. ESR detection of wheat flour before and after irradiation. Spectrochimica Acta A, 63: 888-890.

Ukai, M., Kameya, H., Nakamura, H., Shimoyam, Y. 2008. An electron spin resonance study of dry vegetables before and after irradiation. Spectrochimica Acta A, 69: 1417-1422.

Vivekanandhan, S., Christensen, L., Misra, M., Mohanty, A.K. 2012. Green process for impregnation of silver nanoparticles into microcrystalline cellulose and their antimicrobial bionanocomposite films. Journal of Biomaterials and Nanobiotechnology, 3: 371-376.

Wu, S.C., Hsu, H.C., Wu, Y.N., Ho, W.F. 2011. Hydroxyapatite synthesized from oyster shell powders by ball milling and heat treatment. Materials Characterization, 2: 1180-1187.

www.tarim.gov.tr/GKGM/Belgeler/.../Takviye_Gidal ar_Soru_Cevap.docx, (30.05.2015).

Yarbasi, Z., Karabulut, B., Karabulut, A. 2011. An EPR study of gamma irradiated medicinal plants: Cress seeds and mistletoe. Gazi University Journal of Science, 2: 203-207.

Yoon, H., Park, S., Lee, K., Park, J. 2004. Oyster shell as substitute for aggregate in mortar. Waste Manage Research, 22: 158-170.

Zeng, R.Y., He, R.T., Wei, W., Xu, X.Y., Zhang, X.P., Luo, X., Zheng, L.Y. 2010. Antioxidant properties of polysaccharides from Ganoderma sinense by different cultivations. Food Science and Technology Research, 2: 143-148. 